\title{
A Case of Morbid Obesity with Related Complications
}

\author{
M A Rahman1, T Haque2, A H Amin 3
}

\begin{abstract}
We are reporting a case of morbid obesity with related complications. This unfortunate 32 years old poor gentleman has been suffering from morbid obesity since his early childhood and presented to us with palpitation, shortness of breadth on exertion and chest pain, difficulty in micturation $\begin{array}{llll}\text { for } & \text { the } & \text { last } & \end{array}$

Key Words: Morbid Obesity, Hypertention, Left Ventricular Hypertrophy.

\section{Introduction}

"Overweight" technically refers to an excess of body weight, where as "Obesity" refers to an excess of fat1. The Body Mass Index(BMI) is the accepted standard measure of overweight and obesity2, BMI provides a guideline for weight in relation to height and is equal to the body weight divided by the height in meter squared. Adults with a BMI between 25 and 30 are considered Overweight; those with a BMI of 30 are considered to be Obese. In adults, a BMI threshold of $40 \mathrm{~kg} / \mathrm{m} 2$, distinguishes individuals with severe obesity and the high risks for co-morbidities. This category is sometimes termed as "Class III Obesity" or "Super Obesity" or "Morbid Obesity".
\end{abstract}

1.Muhammad Ashiqur Rahman

Senior Consultant Cardiology, BMCH

Dhanmondi, Dhaka.

2. Tauhidul Haque

Associate Professor Cardiology

Bangladesh Medical College Hospital (BMCH)

Dhanmondi, Dhaka.

3. Ahsanul Haq Amin

Assistant Professor Endocrinology

Bangladesh Medical College Hospital (BMCH)

Dhanmondi, Dhaka.

Corresponding author

Dr.Md.Ashiqur Rahman

Email:docashiq@bol-online.com
Clinically the patient has been diagnosed as a case of Morbid Obesity with Left Ventricular Hypertrophy \& Heart Failure, with Diabetes Mellitus, and Urethral Stricture. After meticulous search for all secondary causes of morbid obesity the reason for his obesity was considered

as

Genetic.

The term "Morbid Obesity" is sometimes used to identify individuals with obesity related co-morbidities. The likelihood of persistence of childhood obesity into adulthood is related to age,3-5 parental obesity,6-7 and severity of obesity.8-9 In longitudinal studies, approximately those 50 percent of obese 6 -years old children, and 80 percent of obese 10 to 14 years old children, who had one obese parent. Girls are more prone than boys to develop persistent obesity during adolescence.11 This is related to changes in body composition that occur at puberty, when body fat decreases in boys and increases in girls. 12

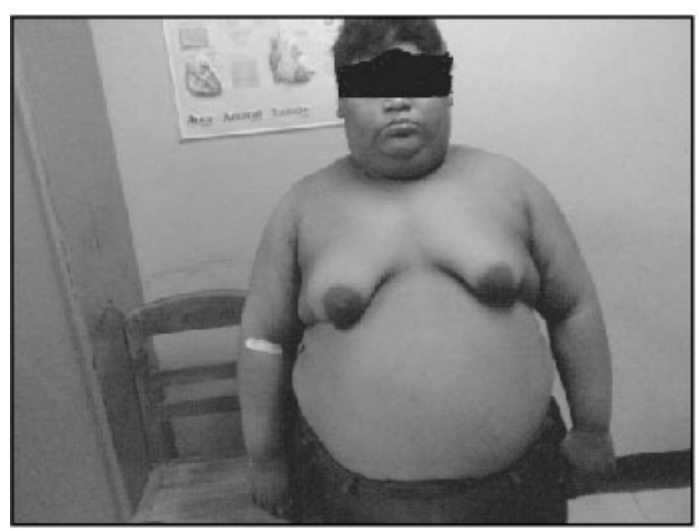

Photograph of a man with Morbid Obesity. 


\section{Case Report}

A thirty two years old fourth class Government employee, visited us at $\mathrm{BMCH}$. He was presented to us with hypertension, palpitation, shortness of breadth on exertion and chest pain, difficulty in micturation for the last 8 years, which was progressive in nature. Occasional vertigo feelings has also been associated.

In the early 2008 he experienced sudden stoppage of urine which was probably due to overgrowth of urethral tissue leading to Bladder Neck Obstruction. Local Doctor did urethral catheterization on several occasion. Thereafter he did self catheterization by using unsterile catheter and had bad type of urinary tract infection. Again he developed difficulty in passing urine and attended Urology Department of $\mathrm{BMCH}$ where he was admitted and surgically treated for Stricture Urethra.

This Gentleman has three obese brothers and two normal sisters. His parents are of normal size and shape. He has started gaining weight since his early childhood.

On General Examination This obese Gentleman looked anxious and obese. His weight was $129 \mathrm{~kg}$ and height was 1 meter 53 centimeter. His Body
Mass Index(BMI) was 54.5. His ideal body weight for height should be $57 \mathrm{~kg}$. To achieve target body weight he has to lose $72 \mathrm{~kg}$ body weight. He was cooperative and his dicubitus was on choice. He was mildly anemic and jaundice, clubbing, koilonychias were absent.

His respiration rate was 16 beats per minute, temperature was normal and Blood Pressure, Systolic 155mmHg, Diastolic $100 \mathrm{mmHg}$. His neck veins could not be seen as they were burried under the thick fat pad in the neck. Both thyroid gland and lymph nodes were not enlarged. Bilateral moderate paedal oedema and gynaemastia were present.

On precordial examination On inspection, Apex beat was seen in left 6th intercostal space $2.5 \mathrm{~cm}$ lateral to the left mid clavicular line. No other visible pulsation could be seen.

On palpation, No thrill or palpable heart sounds were felt.

On auscultation, heart sounds were soft as if heard from distance. Bilateral basal creps were present.

Except Liver, which was soft in consistency with sharp margin and enlarged $5 \mathrm{~cm}$ from the costal margin in the mid clavicular line. Examination of other systems revealed no other abnormalities.

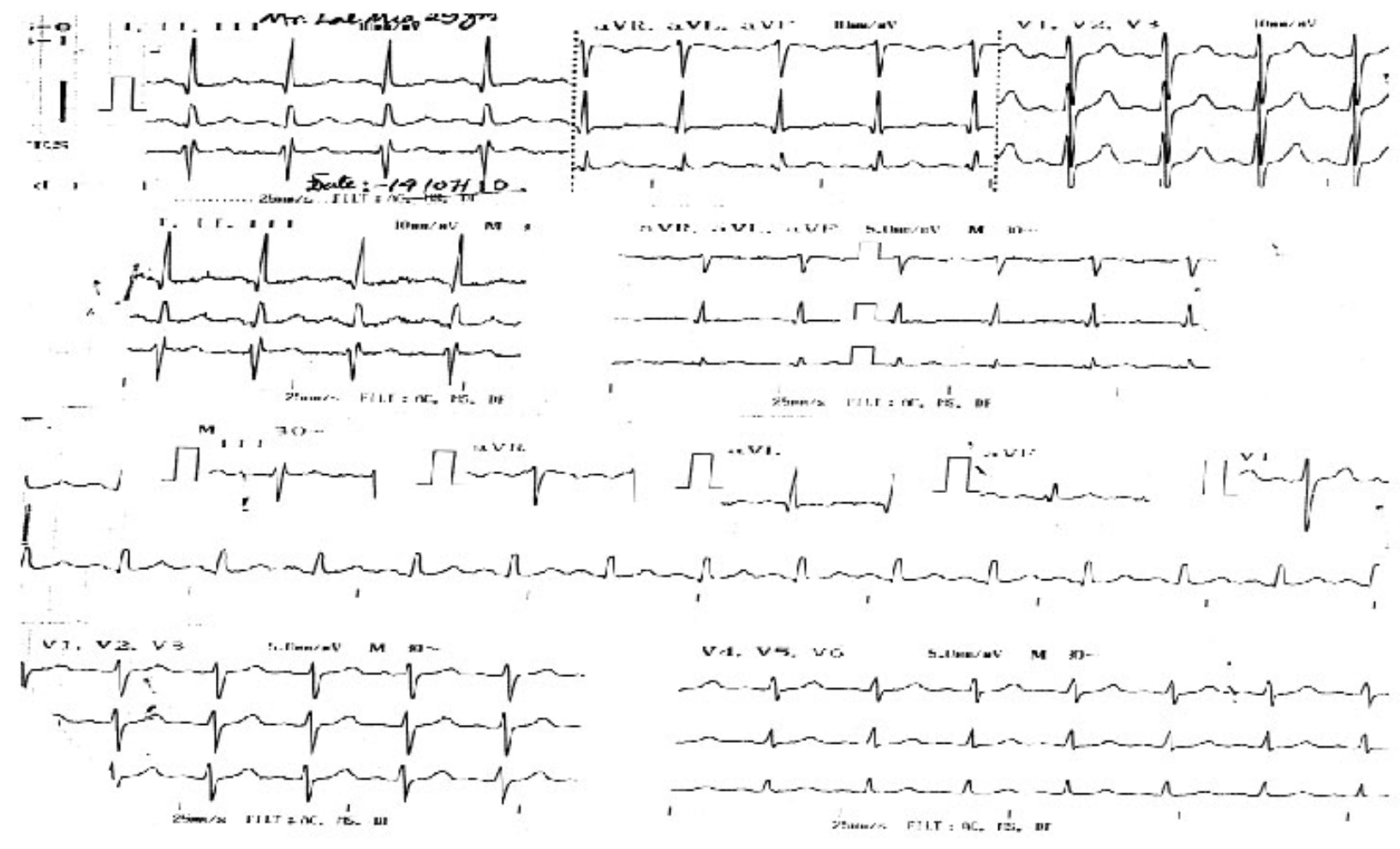




\section{Electrocardiogram(ECG)}

ECG Shows Sinus rhythm with ventricular rate of 94 beats per minute. Broad P wave was noted in lead II \&V1 indicating Left Atrial Hypertrophy. QRS axis shows Left Axis Deviation.T waves were flat in lead I, aVL indicated High Lateral Ischemia. Voltage criteria for LVH were met as evidenced by R wave in lead aVL > 11mm \& Rwave in lead I plus S wave in lead III $>35 \mathrm{~mm}$.(Note: Estes criteria for Left Ventricular Hypertrophy (LVH): 3 Points for Voltage, 3 Points for Repolarization changes, 3 Points for Left Atrial Hypertrophy, 2 Points for Left Axis Deviation, 1 Point for Widened QRS duration, 1 Point for Delayed Intrinsicoid.
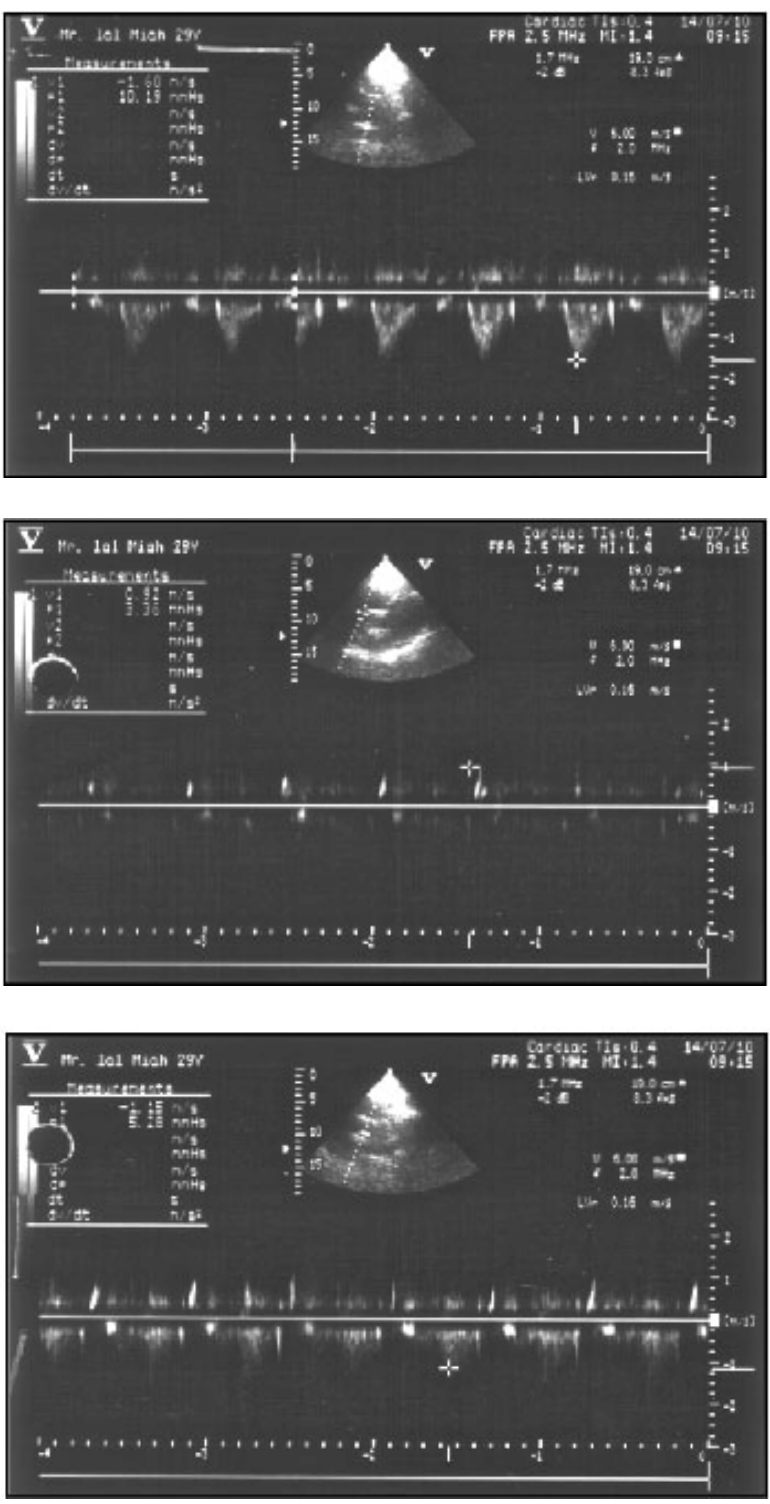

Deflection. 5 or more points are Diagnostic; 4 points are Probable of LVH.) Our patient earned 8 points of Estes criteria for the diagnosis of Left Ventricular Hypertrophy (LVH).

So ECG was consistent with Left Ventricular Hypertrophy with Left Atrial Hypertrophy with High Lateral Ischemia.

LVH defined by LVM/height was more sensitive than LVM/body surface area to identify obesity related LVH and was most consistently associated with cardiovascular events and all-cause death.13

Obese individuals (BMI>30kg/m2 $) 14$ are significantly more likely to develop Atrial Fibrillation when compared to transient or intermittent Atrial Fibrillation.15
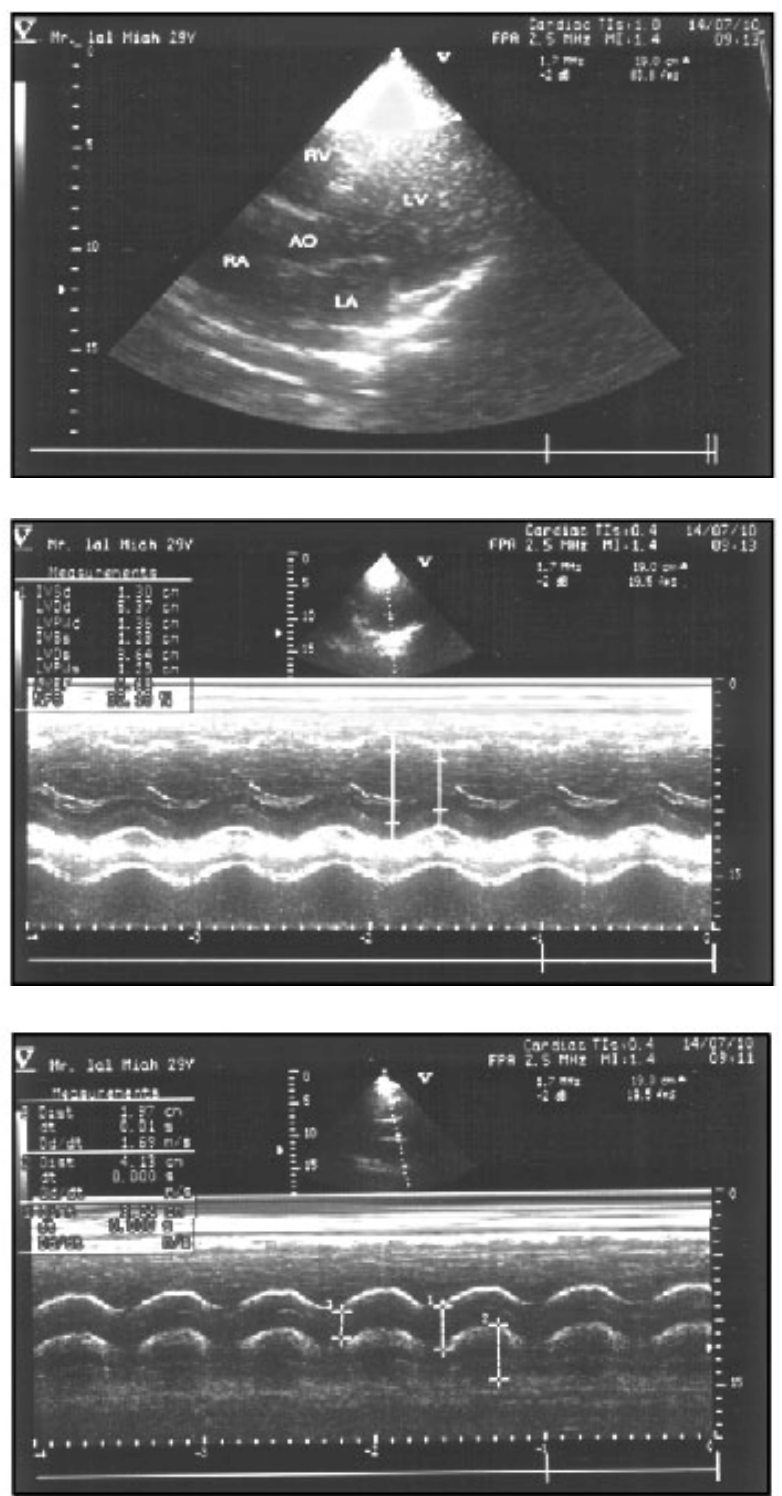
Transthoracic Echocardiogram : Both Left Parasternal Long axis view and Apical view showed normal chamber dimention with good LV Systolic Function (EF\%69\%). Mmode showed Concentric Left Ventricular Hypertrophy.

Routine Tests: CBC showed Hb\% $11.10 \mathrm{gm} / \mathrm{dl}$, ESR $80 \mathrm{~mm}$ in 1st hour. Urine RME showed plenty Pus cells with trace Albumin.

Special Tests: FBS $6.2 \mathrm{mmol} / \mathrm{L}$, Total Cholesterol $280 \mathrm{mg} / \mathrm{dl}$, HDL 36 mg/dl, LDL180 mg/dl, TG360 mg/dl, UriccAcid 7.9 mg/dl Thyroid Function Test showed normal study.

Treatment Plan: As initial management of this obese person we planned for life style intervention, a combination of diet, exercise, and behavioral modification. In addition antihypertensive, antilipid, weight reducing drugs are prescribed. As the patient was poor, so, the patient was managed by medical therapy and our plan for Bariatric surgery could not be implemented.

\section{Discussion :}

Obesity is a curse for both the person individual as well for the society. Greater BMI is associated with increased rate of death from all causes and from cardiovascular disease. This is particularly true for those with severe obesity,16 although only being overweight also appears to be associated with decreased survival.7-19 The association between BMI and cause specific mortality was illustrated in the prospective studies collaboration analysis. The risk of premature death increased with higher BMIs at age 18 years; for a BMI at age18 of 18.5 to $21.9,22$ to $24.9,25$ to 29.9 , and $=30 \mathrm{~kg} / \mathrm{m} 2$, the hazard ratio for premature death was 0.98,1.18,1.66, and 2.79,respectively.20Among 3457subjects in the Framingham Study, those who were both obese and smoked lived 13 to 14 years less than normal-weight nonsmokers21.

A curvilinear relationship between BMI and the risk of type II Diabetes was found in women in the Nurses' Health Study.2223 These may be increased further by a sedentary lifestyle or decreased by exercise.24 Upper body obesity leads to impaired glucose tolerance and hyperinsulinemia.
Hyperinsulinemia may then raise the blood pressure by increasing sympathetic activity, renal sodium reabsorption, or vascular tone. Weight loss in obese subjects is associated with a decline in blood pressure. 25 For each $1 \mathrm{~kg}$ of weight loss ,the systolic and diastolic blood pressures fall by approximately $1 \mathrm{mmHg} .26$ Obesity is associated with high serum cholesterol, Low Density Lipoprotein (LDL) cholesterol, Very Low Density Lipoprotein (VLDL) cholesterol, and Triglycerides, and a reduction in serum High Density Lipoprotein (HDL) cholesterol of about 5 percent.27-28 There is an important association between obesity and heart failure. In an analysis from the Framingham Heart Study in which almost 6000 individual s without a history of heart failure(mean age 55 years) were followed for a mean of 14 years.29 Heart failure developed in 496(8.4 percent).The risk of heart failure increased 5 percent in men and 7 percent in women for each increment of $1 \mathrm{~kg} / \mathrm{m} 2$ inBMI. In addition to the changes like diabetes and hyperlipidemia, several other endocrine changes are associated with obesity. Disorder of sexual arousal and orgasm may be more common in overweight and obese.30 Obesity is often considered to be Genetic in origin when no obvious secondary cause could be found. Genetic anomalies in the del 9q34 syndrome constitute a novel and recognizable phenotype. Obesity is frequent feature in several other chromosomal anomalies including fragile X, Trisomy 21, and Turner Syndrome.31

\section{Conclusion :}

Obesity is associated with significant excess morbidity and mortality. Secondary causes should be searched for and management of the patient has to be done accordingly. Familial orgenetic causes could be ruled out during prenatal check up by PCR in highly sophisticated centres and termination of pregnancy should be planned thereby. Meticulous weight reduction plan by strictly following Life Style Modification Programme, lipid \& weight reducing drugs should be the primary plan of treatment. Obesity related complications should have to be treated and Bariatric Surgery could be planned if necessary. 


\section{References}

1.Foldmark CE, Lissau I, Moreno LA et al.New insights into the field of children and adolescents' obesity : the European perspective. Int J Obes Relat Metab Disord 2004;28:1189.

2. Deurenberg P, Weststrate JA, Cole TJ. Body Index as a measure of body fatness : age and sexspecific prediction formulas. Br J Nutr 1991;65:105.

3. Guo SS, Roche AF, Chumlea WC et al. The predictive value of childhood body mass index values for over weight at age 35years. Am. J Clin Nutr 1994;59:810.

4. Power C, Lake Cole TJ. Body Mass Index and height from childhood to adulthood in the 1958 British born cohort. Am. J Clin Nutr 1997; 66: 1094.

5. Parson TJ, Power C, Logan S, Summerbell CD. Childhood predictor ofs of adult obesity : a systemic review. Int J Obes Relat Metab Disord 1999;23 Suppl 8:S1.

6.Whitaker RC, Wright JA Pepe, MS, et al. Predicting obesity in young adulthood from childhood and parental obesity. New Engl J Med 1997:337:869.

7.Reilly JJ, Methven E, McDowell ZC, et al. Heath consequences of obesity. Arch Dis Child 2003; 88: 748.

8.Whitlock EP, Williams SB, Gold R, Smith P, Shipman S. Screening and Interventions for Childhood Overweight: A systemic Review for the US Preventive Services Task Force : Systematic Evidence Review. Agency for Healthcare Research and Quality, Rockvillle, MD,2005.

9. Power Lake, JK Cole TJ. Measurement and long term health risks of child and adolescent fatness.Int J Obes Relat Metab Disord 1997; 21 : 507.

10. Garn SM, Lavelle M. Two decde follow-up of fatness inearly childhood. Am J Dis Child 1985;139:181.

11. Gran SM, Cole PE. Do the obese remain obese and learn remain learn? Am J Public Health 1980; 70:351.

12. Mellit ED, Cheek DB. The assessment of body water and fatness from infancy to adulthood. Monogr. Soc Res Child Dev 1970; 35: 12.
13. Juio A. Chirinos; Patric Segers; Marc L. De Buyzere et al. Left Ventricular Mass, allometric Scalling, Normative Values, Effect of obesity, and Prognostic Performance. Hypertension. 2010;56:91.@2010 American Heart Association, Inc.

14. Wang TJ; Parise H; Levy D et al. Obesity and the risk of new onset atrial fibrillation. JAMA 2004 Nov 24;292(20):2471-7.

15. Dublin S; French B; Glazer NL et al. Risk of new onset atrial fibrillation in relation to body mass index. Arch Inter Med. 2006 Nov27; 166(21) :2322-8.

16. M Tiggue K; Larson JC; Valoski A, et al. Mortality and cardiac and vascular outcomes in extremely obese women .JAMA.2006 Jul 5; 296(1): 79-86.

17. Adams, KF, Schatzkin, A, Harris, TB, et al. Overweight, obesity, and mortality in a large prospective cohort of persons 50 to 70 years old. N Eng J Med 2006;355:763.

18. Jee SH,Sull JW Park, J, et al. Body mass index and mortality in Korean men and women. $\mathrm{N}$ Engl $\mathrm{J}$ Med 2006;355:779.

19. Whitlock G; Lewington S; Sherliker P, etal. Body mass index and cause specific mortality in 900000 adults; collaborative analysis of 57 prospective studies. Lancet.2009 Mar 28;373(9669):1083-96.

20. Vav Dam RM; Willett WC; Manson JE; Hu FB.The relationship between overweight in adolescence and premature death in women. Ann Intern Med. 2006 Jul 18; 145(2): 91-7.

21. Peeters A; Barendregt JJ; Willekens F, et al. Obesity in adulthood and its consequences for life expectancy: a life table analysis. Ann Intern Med 2003 Jan7;138(1):24-32.

22. Willett WC, Dietz WH, Colditz GA. Guidelines for healthy weight.N Engl J Med 1999;341:427.

23. Colditz GA, Willett WC, Rotnitzky A, Manson,JE. Weight gain as a risk factor for clinical diabetes mellitus in women.Ann Intern Med 1995;122: 481.

24. Helmrich SP, Ragland DR, Leung RW, Paffenbarger,RS Jr. Physical activity and reduced occurrence of non insulin dependent diabetes mellitus. N Engl Med 1991:325:147. 
25. Haung Z, Willett WC, Manson JE, etal. Body weight, weight change, and risk for hypertension in women. Ann Intern Med 1998;128:81.

26. Neter JE, Stam BE, Kok FJ, Grobbee DE. Influence of wreight reduction on blood pressure: a meta analysis of randomized controlled trials. Hypertension 2003;42:878.

27. Hubert HB; Feinleib M; Mac Namara PM, etal. Obesity as an independent risk factor for cardiovascular disease: a 26 year follow up of participants in the Framingham Heart Study.Circulation 1983 May;67(5):968-77.

28. Grundy SM; Barnett JP. Metabolic and health complications of obesity .Dis Mon 1990 Dec;36912):641-731.

29. Kenchaiah S; Evans JC; Levy D, etal. Obesity and the risk of heart failure.N Engl Med 2002 Aug 1;347(5):305-13.

30. Esposito K; Giugliano F; Ciotola M; De Sio M, et al. Obesity and sexual dysfunction, male and female. Int J Import Res.2008 Jul-Aug;20(4):358-65.Epub 2008 Apr 10.

31. V Cormier-Daire, F Molinari, M Rio, O Raoul et al. Cryptic terminal deletion of chromosome 9q34 : a novel cause of syndromic Obesity in childhood J Med Gent 2003:40:300303 doi:10.1136/jmg.40.4.300. 